\title{
Usual versus tight control of systolic blood pressure in non-diabetic patients with hypertension (Cardio-Sis): an open-label randomised trial
}

\author{
Paolo Verdecchia, Jan A Staessen, Fabio Angeli, Giovanni de Simone, Augusto Achilli, Antonello Ganau, Gianfrancesco Mureddu, Sergio Pede, \\ Aldo P Maggioni, Donata Lucci, Gianpaolo Reboldi, on behalf of the Cardio-Sis investigators*
}

\section{Summary}

Background The level to which systolic blood pressure should be controlled in hypertensive patients without diabetes remains unknown. We tested the hypothesis that tight control compared with usual control of systolic blood pressure would be beneficial in such patients.

Methods In this randomised open-label trial undertaken in 44 centres in Italy, 1111 non-diabetic patients with systolic blood pressure $150 \mathrm{~mm} \mathrm{Hg}$ or greater were randomly assigned to a target systolic blood pressure of less than $140 \mathrm{~mm} \mathrm{Hg}$ (usual control; $n=553$ ) or less than $130 \mathrm{~mm} \mathrm{Hg}$ (tight control; $n=558$ ). After stratification by centre, we used a computerised random function to allocate patients to either group. Observers who were unaware of randomisation read electrocardiograms and adjudicated events. Open-label agents were used to reach the randomised targets. The primary endpoint was the rate of electrocardiographic left ventricular hypertrophy 2 years after randomisation. Analysis was by intention to treat. This study is registered with ClinicalTrials.gov, number NCT00421863.

Results Over a median follow-up of 2.0 years (IQR 1.93-2.03), systolic and diastolic blood pressure were reduced by a mean of $23.5 / 8.9 \mathrm{~mm} \mathrm{Hg}(\mathrm{SD} \mathrm{10} \cdot 6 / 7 \cdot 0)$ in the usual-control group and by $27 \cdot 3 / 10 \cdot 4 \mathrm{~mm} \mathrm{Hg} \mathrm{(11.0/7.5)} \mathrm{in} \mathrm{the}$ tight-control group (between-group difference $3.8 \mathrm{~mm} \mathrm{Hg}$ systolic [95\% CI 2.4-5.2], p<0.0001; and 1.5 mm $\mathrm{Hg}$ diastolic [0.6-2.4]; $\mathrm{p}=\mathbf{0} \cdot 041)$. The primary endpoint occurred in 82 of 483 patients $(17 \cdot 0 \%)$ in the usual-control group and in 55 of 484 patients $(11 \cdot 4 \%)$ of the tight-control group (odds ratio $0 \cdot 63 ; 95 \%$ CI $0 \cdot 43-0 \cdot 91 ; p=0 \cdot 013$ ). A composite cardiovascular endpoint occurred in $52(9.4 \%)$ patients in the usual-control group and in $27(4.8 \%)$ in the tightcontrol group (hazard ratio $0 \cdot 50,95 \%$ CI $0 \cdot 31-0 \cdot 79 ; p=0 \cdot 003$ ). Side-effects were rare and did not differ significantly between the two groups.

Interpretation Our findings lend support to a lower blood pressure goal than is recommended at present in non-diabetic patients with hypertension.

Funding Boehringer-Ingelheim, Sanofi-Aventis, Pfizer.

\section{Introduction}

The relation between the incidence of stroke or coronary heart disease and blood pressure is continuous at all ages. ${ }^{1}$ Furthermore, a reduction in systolic blood pressure has explained most of the treatment benefit in outcome trials in patients with hypertension. ${ }^{2}$ Hypertension guidelines recommend that systolic and diastolic blood pressure be reduced to values less than $140 / 90 \mathrm{~mm} \mathrm{Hg}^{3,4}$ or $140 / 85 \mathrm{~mm} \mathrm{Hg}{ }^{5}$ Present evidence lends supports to reduced thresholds of diastolic blood pressure in patients with type 2 diabetes, ${ }^{6-9}$ but clinical trials do not support the intensive lowering of mean arterial pressure in patients with renal dysfunction. ${ }^{10}$

The 2007 guidelines of the European Society of Hypertension $^{3}$ and a recent editoria ${ }^{11}$ have emphasised that the value to which systolic blood pressure should be lowered in patients with hypertension is unknown and that this issue should be regarded as an urgent research priority. In the Studio Italiano Sugli Effetti CARDIOvascolari del Controllo della Pressione Arteriosa SIStolica (Cardio-Sis) trial, ${ }^{12}$ we tested the hypothesis that tight control
(<130 mm Hg) compared with usual control (<140 mm Hg) of systolic blood pressure would be beneficial in non-diabetic patients with hypertension..$^{13,14}$

\section{Methods}

Patients

We have previously described the design of Cardio-Sis in detail.12 Briefly, we enrolled patients aged 55 years or older with a systolic blood pressure of $150 \mathrm{~mm} \mathrm{Hg}$ or higher, who had been receiving antihypertensive treatment for at least 12 weeks. Patients were enrolled from 44 centres in Italy between Feb 22, 2005, and Feb 28, 2007. Eligible patient had to have at least one additional risk factor, as described in the guidelines of the European Society of Hypertension ${ }^{3}$ (cigarette smoking, total cholesterol $\geq 5 \cdot 2 \mathrm{mmol} / \mathrm{L}, \mathrm{HDL}$ cholesterol $<1.0 \mathrm{mmol} / \mathrm{L}$, LDL cholesterol $\geq 3.4 \mathrm{mmol} / \mathrm{L}$, family history of premature cardiovascular disease in first degree relative $[<65$ years in women and $<55$ years in men], previous transient ischaemic attack or stroke, or established coronary or peripheral arterial disease). We
Lancet 2009; 374: 525-33 *Members listed at end of paper Division of Cardiology, Hospital S Maria della Misericordia, Perugia, Italy (P Verdecchia MD FAngeli MD); Division of Hypertension and Cardiac Rehabilitation, Department of Cardiovascular Diseases, University of Leuven, Leuven, Belgium (Prof J A Staessen MD), Department of Epidemiology, Maastricht University, Maastricht, Netherlands (Prof J A Staessen); Department of Clinical and Experimental Medicine, University Federico II, Napoli, Italy (Prof G de Simone MD); Division of Cardiology, Belcolle Hospital, Viterbo, Italy (A Achilli MD); Department of Internal Medicine, Cardiology Unit, University of Sassari, Sassari, Italy (Prof A Ganau MD); Department of Cardiovascular Diseases, Hospital S Giovanni Addolorata, Rome, Italy (G Mureddu MD); Division of Cardiology, Hospital S Pietro Vernotico, San Pietro Vernotico, Italy (S Pede MD); ANMCO Research Centre, Firenze, Italy (A P Maggioni MD, Donata Lucci MSc); and Department of Internal Medicine, University of Perugia, Perugia, Italy (G Reboldi MD)

Correspondence to: Paolo Verdecchia, Cardio-Sis Coordinating Centre, ANMCO Research Centre, Via La Marmora 34, I-50121 Florence, Italy verdec@tin.it 


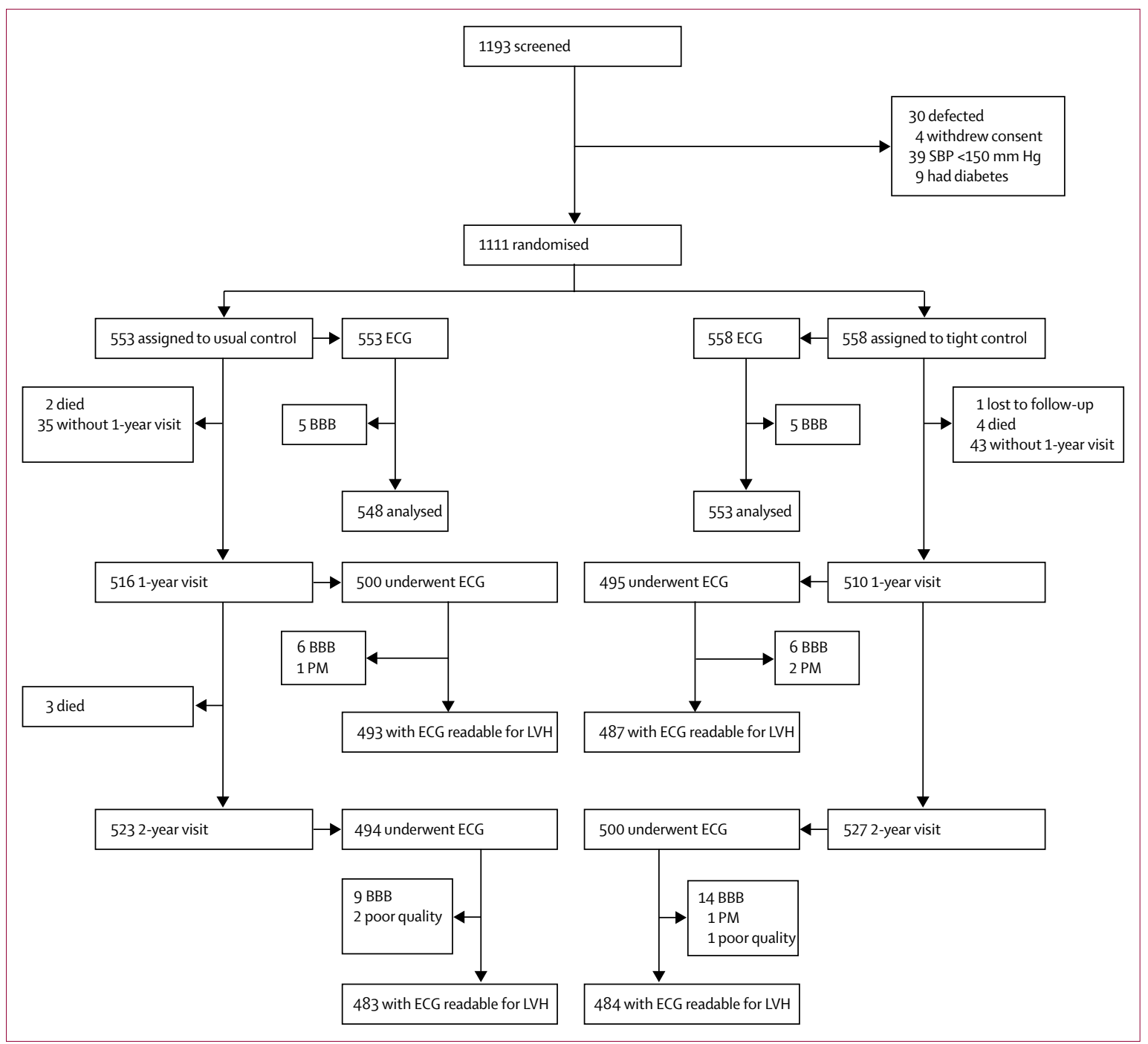

Figure 1: Trial profile

$\mathrm{SBP}=$ systolic blood pressure. $\mathrm{ECG}=$ electrocardiogram. $\mathrm{LVH}=$ left ventricular hypertrophy. $\mathrm{BBB}=$ left or right bundle branch block. $\mathrm{PM}=$ pacemaker.

excluded patients with a fasting glucose of $7.0 \mathrm{mmol} / \mathrm{L}$ or higher and those with a history of diabetes, because existing evidence ${ }^{6-9}$ lends supports to intensive lowering of diastolic blood pressure in such patients and because present guidelines recommend tight blood-pressure control in patients with diabetes..$^{3-5}$ Other exclusion criteria were any disease reducing life expectancy, renal dysfunction (serum creatinine $>176.8 \mu \mathrm{mol} / \mathrm{L}$ ), clinically relevant hepatic or haematological disorders, valvular heart disease, disorders confusing the electrocardiographic diagnosis of left ventricular hypertrophy (completerightorleftbundleblock, Wolff-Parkinson-White syndrome, previous Q-wave myocardial infarction, and paced heart rhythm), atrial fibrillation, and substance misuse. The ethics review committee of each participating centre approved the protocol, and all patients provided written informed consent.

\section{Randomisation and masking}

Eligible patients entered a run-in period to ascertain that at two visits 7-14 days apart their systolic blood pressure on their present antihypertensive drug treatment was $150 \mathrm{~mm} \mathrm{Hg}$ or higher. ${ }^{12}$ After stratification by centre, we used a computerised random function to allocate patients in a 1:1 ratio to tight $(<130 \mathrm{~mm} \mathrm{Hg})$ or usual control ( $<140 \mathrm{~mm} \mathrm{Hg}$ ) of systolic blood pressure.Randomisation was done with a fully computerised system, with the group assignment concealed and blocks of four patients per site. Field investigators entered patient's data into the system, which verified the appropriateness of each patient for randomisation on the basis of inclusion and exclusion criteria. After all steps were completed successfully, a randomisation code was provided by the system and patients were assigned in an open manner to one of the two groups. 


\begin{tabular}{|c|c|c|}
\hline & $\begin{array}{l}\text { Usual control } \\
(\mathrm{n}=553)\end{array}$ & $\begin{array}{l}\text { Tight control } \\
(\mathrm{n}=558)\end{array}$ \\
\hline Age (years) & $67(7)$ & $67(7)$ \\
\hline Body-mass index $\left(\mathrm{kg} / \mathrm{m}^{2}\right)$ & $27 \cdot 8(4 \cdot 0)$ & $27 \cdot 8(4 \cdot 3)$ \\
\hline Waist circumference $(\mathrm{cm})$ & $98.5(11.6)$ & $98 \cdot 6(12 \cdot 2)$ \\
\hline Systolic pressure $(\mathrm{mm} \mathrm{Hg})$ & $163 \cdot 3(11 \cdot 1)$ & $163 \cdot 3(11 \cdot 3)$ \\
\hline Diastolic pressure $(\mathrm{mm} \mathrm{Hg})$ & $89.7(8.8)$ & $89.6(8.8)$ \\
\hline Heart rate (beats per min) & $70 \cdot 4(10 \cdot 7)$ & $71 \cdot 2(10 \cdot 2)$ \\
\hline Serum creatinine ( $\mu \mathrm{mol} / \mathrm{L})$ & $83.8(18.6)$ & $83 \cdot 2(19 \cdot 4)$ \\
\hline Glucose (mmol/L) & $5.43(0.63)$ & $5.46(0.71)$ \\
\hline Total cholesterol (mmol/L) & $5.63(1.14)$ & $5.57(1.0)$ \\
\hline HDL cholesterol (mmol/L) & $1.50(0.51)$ & $1.50(0.50)$ \\
\hline LDL cholesterol (mmol/L) & $3.40(0.98)$ & $3.38(0.94)$ \\
\hline Women & $324(59 \%)$ & $329(59 \%)$ \\
\hline Current cigarette smoking & $115(21 \%)$ & $120(22 \%)$ \\
\hline Dyslipidaemia* & $425(77 \%)$ & $418(75 \%)$ \\
\hline Coronary artery disease & $69(13 \%)$ & $59(11 \%)$ \\
\hline Stroke or transient ischaemic attack & $49(9 \%)$ & $42(8 \%)$ \\
\hline Occlusive arterial disease & $11(2 \%)$ & $19(3 \%)$ \\
\hline \multicolumn{3}{|l|}{ Drugs } \\
\hline Diuretics & $259(47 \%)$ & $226(41 \%)$ \\
\hline$\beta$ blockers & $212(38 \%)$ & $180(32 \%)$ \\
\hline ACE inhibitors & $243(44 \%)$ & $245(44 \%)$ \\
\hline Angiotensin-receptor blockers & $159(29 \%)$ & $193(35 \%)$ \\
\hline Calcium-channel blockers & $196(35 \%)$ & $184(33 \%)$ \\
\hline$\alpha 1$ blockers & $52(9 \%)$ & $50(9 \%)$ \\
\hline Centrally acting drugs & $13(2 \%)$ & $13(2 \%)$ \\
\hline Statins & $128(23 \%)$ & $125(22 \%)$ \\
\hline Aspirin & $104(19 \%)$ & $107(19 \%)$ \\
\hline \multicolumn{3}{|c|}{$\begin{array}{l}\text { Data are mean (SD) or number (\%). ACE=angiotensin-converting enzyme. } \\
{ }^{*} \text { Dyslipidaemia is a total cholesterol of } 5 \cdot 2 \mathrm{mmol} / \mathrm{L} \text { or more, an } \mathrm{HDL} \text { cholesterol o } \\
\text { less than } 1.0 \mathrm{mmol} / \mathrm{L} \text {, or an } \mathrm{LDL} \text { cholesterol of } 3.4 \mathrm{mmol} / \mathrm{L} \text { or more at } \\
\text { randomisation. }\end{array}$} \\
\hline
\end{tabular}

The steering committee was responsible for the scientific integrity, conduct, and publication of the trial. An endpoint committee, unaware of the randomisation code, adjudicated all incident clinical events according to published diagnostic criteria ${ }^{12}$ on the basis of the records provided by the clinical investigators. The coordinating office was located at the research centre of the Italian Association of Hospital Cardiologists (ANMCO) in Florence, Italy. Blinded experts, unaware of the randomisation group, read all electrocardiograms at a central facility.

\section{Outcomes}

The primary study outcome was the prevalence of electrocardiographic left ventricular hypertrophy at the final 2-year visit. ${ }^{12}$ This endpoint is an intermediate outcome that is a strong predictor of cardiovascular outcomes. ${ }^{15,16}$ According to the validated Perugia score, ${ }^{17,18}$ the diagnosis of left ventricular hypertrophy required at least one of three criteria: (1) modified Cornell voltage

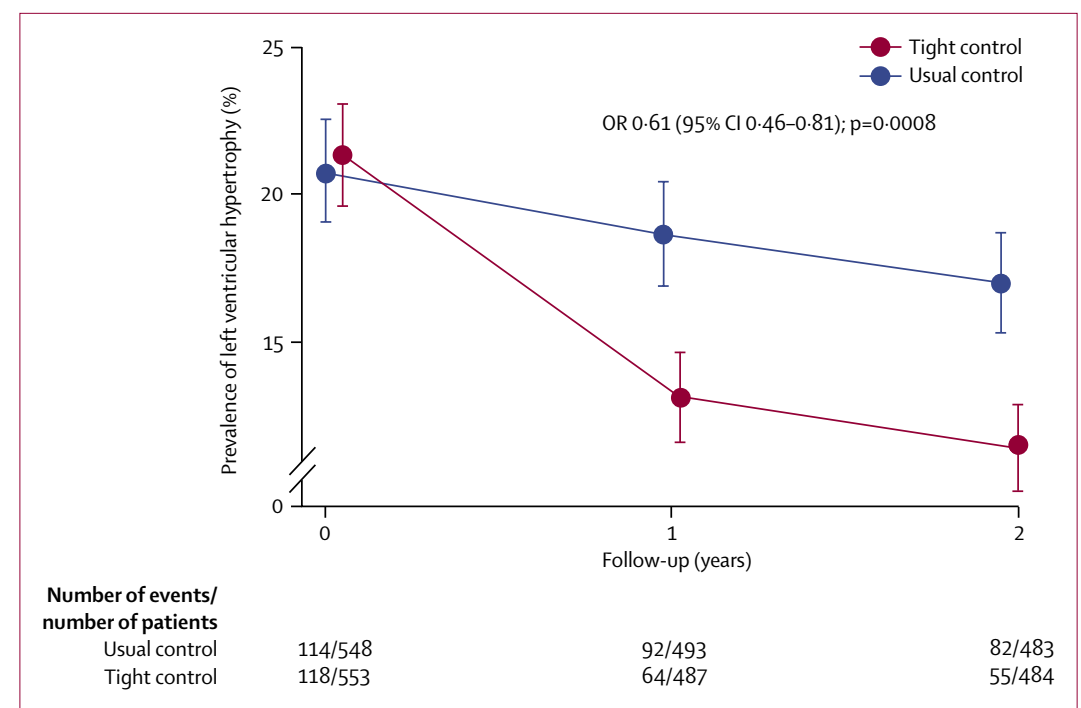

Figure 2: Rate of left ventricular hypertrophy by randomisation groups at baseline and follow-up The odds ratio (OR) was estimated by the PROC GENMOD procedure, taking into account the randomised groups, the time of observation, the group-by-time interaction, and the rate of left ventricular hypertrophy at entry. Error bars denote $95 \% \mathrm{Cls}$.

(SV3+RaVL $>2.0 \mathrm{mV}$ in women and $>2.4 \mathrm{mV}$ in men); (2) left ventricular strain (inverted asymmetric $T$ wave with flat or downsloping ST-segment and at least 0.05 mV depression $80 \mathrm{~ms}$ after the J point); or (3) a Romhilt-Estes score of 5 or more. ${ }^{19}$ The main prespecified ${ }^{12}$ secondary outcome was a composite of all-cause mortality, fatal or non-fatal myocardial infarction, fatal or non-fatal stroke, transient ischaemic attack, congestive heart failure of New York Heart Association stages III or IV requiring admission to hospital, angina pectoris with objective evidence of myocardial ischaemia, new-onset atrial fibrillation, coronary revascularisation, aortic dissection, occlusive peripheral arterial disease, and renal failure requiring dialysis. Other predefined ${ }^{12}$ secondary outcomes were the single components of the main secondary outcome and the baseline-adjusted difference between groups in the achieved systolic blood pressure.

\section{Procedures}

After randomisation, patients were followed up every 4 months for 2 years. ${ }^{12}$ At every visit, physicians measured blood pressure by auscultation (diastolic phase 5), with standard mercury sphygmomanometers, after patients had been seated for at least $10 \mathrm{~min}$. Blood pressure was the average of three consecutive readings at every visit. At the second run-in visit and at 1 and 2 years, patients had a 12-lead electrocardiogram and biochemical blood tests (total cholesterol and HDL and LDL cholesterol, glucose, creatinine, and potassium). Patients not attending one or more visits remained in follow-up by telephone.

Treatment to lower blood-pressure was open label and tailored to every patient's needs. Antihypertensive drug treatment included various combinations of 
For more on Clinical Research Technology S.r.I see http:// www.cr-technology.com For the Cardio-Sis website see http://www.cardio-sis.it

previous drugs (background therapy) plus drugs made available for the purpose of the study. We dispensed furosemide (25 mg per day), ramipril $(5 \mathrm{mg}$ or $10 \mathrm{mg}$ per day), telmisartan (80 $\mathrm{mg}$ per day), amlodipine ( $5 \mathrm{mg}$ or $10 \mathrm{mg}$ per day), bisoprolol (5 mg per day), and transdermal clonidine $(2.5 \mathrm{mg}$ or $5.0 \mathrm{mg}$ per day). Ramipril and telmisartan were also available in fixed combinations with hydrochlorothiazide $(12.5 \mathrm{mg}$ or $25.0 \mathrm{mg}$ per day for ramipril, and $12.5 \mathrm{mg}$ per day for telmisartan). At every visit, the choice of drugs in individual patients was left to the discretion of the investigators. In the tight-control group, one systolic blood-pressure reading higher than $130 \mathrm{~mm} \mathrm{Hg}$ at any visit led to intensification of treatment. Conversely, in the usual-control group, achievement of a systolic blood pressure below $130 \mathrm{~mm} \mathrm{Hg}$ entailed downtitration of treatment.

We tested the inter-reader degree of agreement for the categorical diagnosis of left ventricular hypertrophy (absent or present) in a random sample of 200 patients. There was agreement between the two readers in 193 of 200 tracings ( $\kappa$ statistic $0 \cdot 89,95 \%$ CI $0 \cdot 81-0 \cdot 97$;

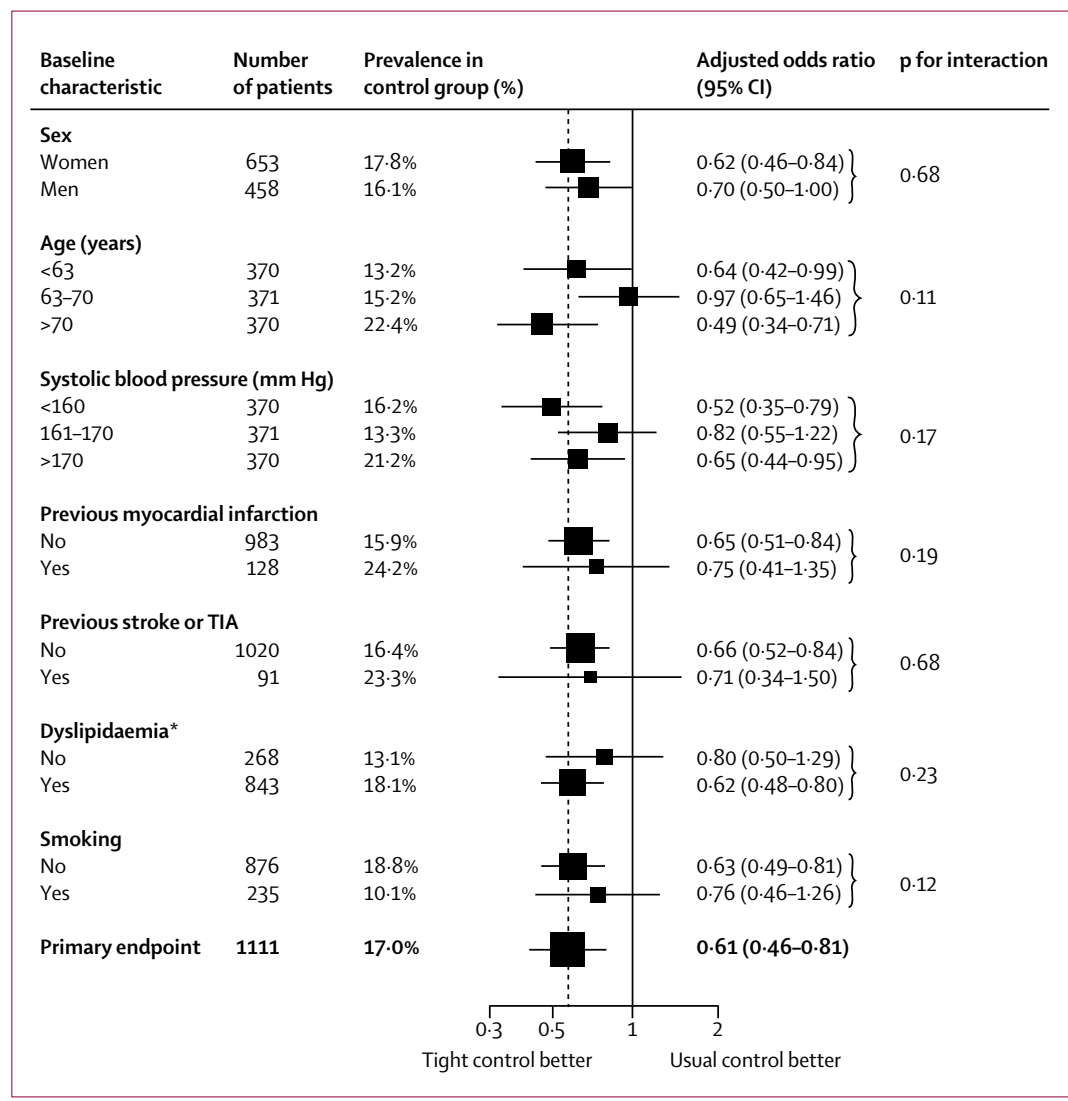

Figure 3: Sensitivity analyses for the primary outcome

The odds ratios were estimated by the PROC GENMOD procedure, taking into account the randomised groups, the time of observation, the group-by-time interaction, and the rate of left ventricular hypertrophy at entry. The rate in the control group was determined at the final (2-year) visit. TIA=transient ischaemic attack. ${ }^{*}$ Dyslipidaemia is a total cholesterol of $5.2 \mathrm{mmol} / \mathrm{L}$ or more, an $\mathrm{HDL}$ cholesterol less than $1.0 \mathrm{mmol} / \mathrm{L}$, or an LDL cholesterol of $3.4 \mathrm{mmol} / \mathrm{L}$ or more at randomisation. $\mathrm{p}<0 \cdot 0001)$. Under supervision of the steering committee, Clinical Research Technology S.r.l., Salerno, Italy developed the clinical-report forms, which ran entirely on the Cardio-Sis website. The quality of the electronic data was checked against the source documents by on-site audits undertaken every 6 months and at the end of the study. Drug supply to the clinical centres was automated on the basis of the information in the submitted electronic case-report forms.

\section{Statistical analysis}

For database management and statistical analysis, we used the SAS package (version 9.1.3). We computed sample size, assuming that the prevalence of left ventricular hypertrophy would be $25 \%$ at enrolment, and $19 \%$ in the usual-control group and $12 \%$ in the tight-control group at the final 2-year visit. To show a $7 \%$ absolute difference between the groups in the prevalence of left ventricular hypertrophy on two-sided tests with an $\alpha$-level of 0.05 and 0.85 power, assuming a drop-out rate of $12 \%$ over 2 years, 1100 patients (550 per group) needed to be randomly assigned.

Analysis was by intention to treat with all available data. We compared means by the standard normal $Z$ test and proportions by $\chi^{2}$ analysis. We used logistic regression analysis to compare the primary outcome in the two groups. We used general estimating equations (categorical variables) or linear mixed models (continuous variables), as implemented in the PROC GENMOD and PROC MIXED procedures of the SAS package, with patients set as the random effect. We assessed the incidence of events, with Kaplan-Meier survival function estimates, the log-rank test, and Cox regression. In these analyses, we considered only the first event for each type of outcome.

This trial is registered withClinicalTrials.gov, number NCT00421863.

\section{Role of the funding source}

The sponsors of the study had no role in the design or the conduct of the trial, data collection, database management, statistical analysis, interpretation of the results, or writing of the report. The members of the steering committee and the writing committee had full access to the database and had final responsibility for the decision to submit for publication.

\section{Results}

Figure 1 shows the trial profile and table 1 the baseline characteristics. Of 1193 patients screened, 1111 (93\%) were randomly assigned: 553 to usual control and 558 to tight control of systolic blood pressure. Median duration of follow-up was 2.0 years (IQR 1.93-2.03). At the end of the study, the number of patient-years was 1013 in the usual-control group and 1060 in the tight-control group. Only one patient, allocated to usual control, was lost to follow-up. 
Blood pressure decreased by $25 \cdot 8 / 9 \cdot 9 \mathrm{~mm} \mathrm{Hg}$ at 1 year and by $27 \cdot 7 / 10 \cdot 8 \mathrm{~mm} \mathrm{Hg}$ at 2 years in the usual-control group, and by $30.5 / 11.4 \mathrm{~mm} \mathrm{Hg}$ at 1 year and $31 \cdot 3 / 12 \cdot 3 \mathrm{~mm} \mathrm{Hg}$ at 2 years in the tight-control group $(\mathrm{p}<0.0001)$. The mean reduction in blood pressure, calculated as the average of all differences in blood pressure between the baseline visit and all subsequent visits, was $23.5 / 8.9 \mathrm{~mm} \mathrm{Hg}$ (SD 10.6/7.0) in the usual-control group and $27 \cdot 3 / 10 \cdot 4 \mathrm{~mm} \mathrm{Hg}$ (SD 11.0/7·5) in the tight-control group. The blood pressure difference between the two groups averaged $3.8 \mathrm{~mm} \mathrm{Hg}$ systolic (95\% CI 2.4-5.2) and $1.5 \mathrm{~mm} \mathrm{Hg}$ diastolic (0.6-2.4). In the mixed model, the time-by-group interaction was significant for both systolic $(\mathrm{p}<0.0001)$ and diastolic ( $\mathrm{p}=0 \cdot 041)$ blood pressure.

The achieved systolic blood pressure was less than $140 \mathrm{~mm} \mathrm{Hg}$ in $64.4 \%(331 / 514)$ of patients at 1-year follow-up and in $66.9 \%(334 / 499)$ at 2-year follow-up in the usual-control group, compared with $75 \cdot 5 \%(385 / 510)$ of patients at 1-year follow-up and $78.7 \%(399 / 507)$ at 2-year follow-up in the tight-control group $(\mathrm{p}<0.0001$ between groups). The achieved systolic blood pressure was less than $130 \mathrm{~mm} \mathrm{Hg}$ in $23.3 \%(120 / 514)$ of patients at 1-year follow-up and $27.3 \%(136 / 499)$ at 2-year follow-up in the usual-control group, compared with $45 \cdot 3 \%(231 / 510)$ of patients at 1-year follow-up and $72 \cdot 2 \%$ $(366 / 507)$ at 2-year follow-up in the tight-control group $(\mathrm{p}<0.0001$ between groups). At the end of the study (2-year visit), blood pressure was $135 \cdot 6 / 78.7 \mathrm{~mm} \mathrm{Hg}$ in the usual-control group and $131.9 / 77.4 \mathrm{~mm} \mathrm{Hg}$ in the tight-control group.

Figure 1 shows the number of patients with electrocardiograms that were interpretable for the diagnosis of left ventricular hypertrophy at 1 and 2 years of follow-up. At the 2-year visit (figure 2), the proportion of patients who achieved the primary outcome was $17.0 \%$ $(82 / 483)$ in the usual-control group and $11.4 \%(55 / 484)$ in the tight-control group (odds ratio [OR] 0.63, $95 \% \mathrm{CI}$ $0 \cdot 43-0 \cdot 91 ; \mathrm{p}=0 \cdot 013)$.

Since the PROC GENMOD analysis showed a strong evidence of a time-by-group interaction $(\mathrm{p}=0 \cdot 018)$, we compared the likelihood of left ventricular hypertrophy in the two groups at all visits. Although the groups did not differ at baseline (OR 1.02, 95\% CI 0.86-1.22; $\mathrm{p}=0 \cdot 80$ ), left ventricular hypertrophy was less likely in the tight-control than in the usual-control group at 1 year $(0.48,0.27-0.84 ; \mathrm{p}=0.010)$ and at 2 years $(0.46$, $0 \cdot 26-0 \cdot 82 ; \mathrm{p}=0 \cdot 008)$. When we examined the two groups separately, the likelihood of left ventricular hypertrophy, compared with baseline, decreased in tight-control group at 1 year (OR 0.38, 95\% CI 0.24-0.59; $<<0 \cdot 0001$ ) and at 2 years $(0 \cdot 31,0 \cdot 20-0 \cdot 47 ; \mathrm{p}<0 \cdot 0001)$. By contrast, the reduction in the likelihood of left ventricular hypertrophy was not significant in the usual-control group both at 1 year $(0 \cdot 82,0 \cdot 51-1 \cdot 30 ; \mathrm{p}=0 \cdot 39)$ and at 2 years $(0 \cdot 68$, $0 \cdot 41-1 \cdot 12 ; \mathrm{p}=0 \cdot 13)$. Sensitivity analyses by prespecified baseline characteristics were confirmatory (figure 3 ).

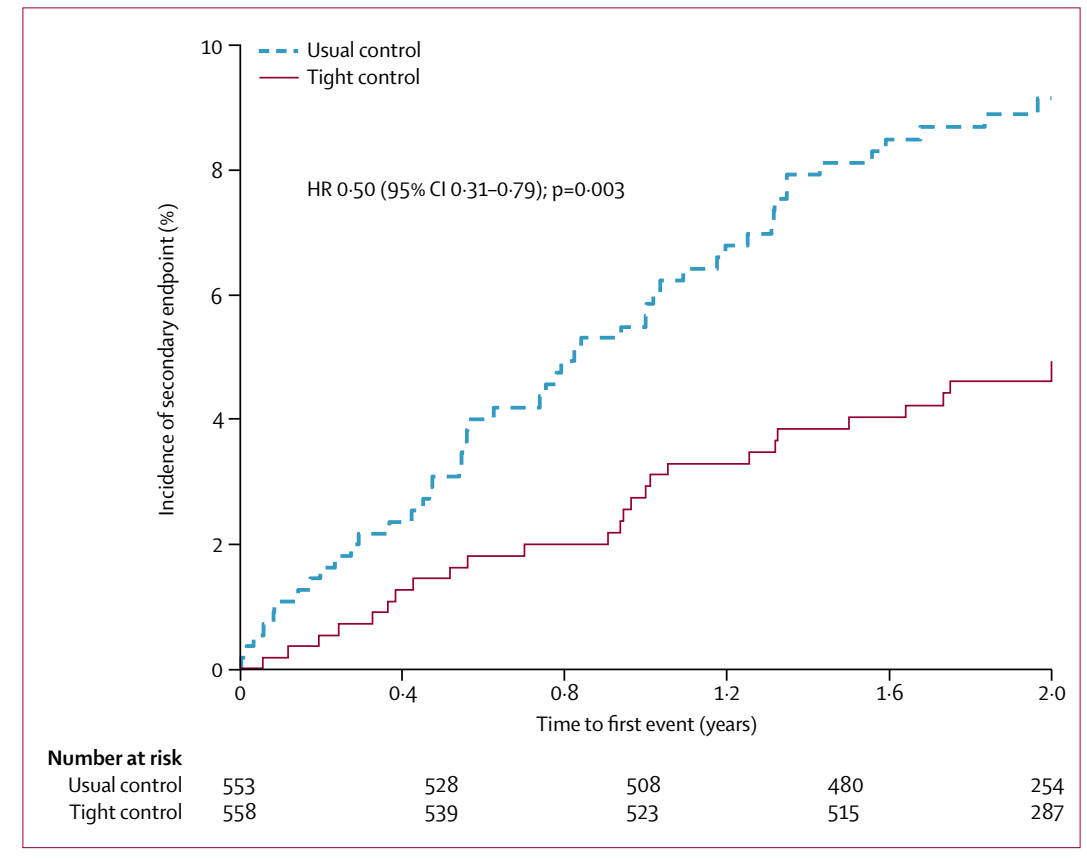

Figure 4: Main composite secondary endpoint in the two groups $\mathrm{HR}=$ hazard ratio.

Figure 4 shows the survival function estimates of the composite secondary outcome by treatment group, which occurred in $52(9.4 \%)$ patients in the usual-control group and in $27(4.8 \%)$ in the tight-control group (hazard ratio [HR] $0 \cdot 50,95 \%$ CI $0 \cdot 31-0 \cdot 79 ; \mathrm{p}=0 \cdot 003$; table 2$)$. The event rate was $5 \cdot 14(95 \%$ CI $3 \cdot 9-6 \cdot 7)$ per 100 patient-years in the usual-control group and $2.54(1 \cdot 75-3 \cdot 72)$ in the tight-control group. With regard to the components of the composite outcome (table 2), new-onset atrial fibrillation and coronary revascularisation occurred less in the tight-control than in the usual-control group (table 2). The incidence of myocardial infarction, admission for heart failure, stroke, transient ischaemic attack, and all-cause death was low and did not differ between the groups (table 2).

Adverse reactions (table 3 ) were rare, generally mild, and occurred at a similar rate in the two treatment groups. One patient in each group had angioedema. One patient in the tight-control group had a severe skin reaction requiring admission to hospital. During follow-up, serum potassium decreased to less than $3.0 \mathrm{mmol} / \mathrm{L}$ in one patient in the usual-control group and in two in the tight-control group $(\mathrm{p}=0.56)$, and glucose concentrations increased to $7.0 \mathrm{mmol} / \mathrm{L}$ or higher in 33 patients in the usual-control group and in 32 in the tight-control group $(\mathrm{p}=0 \cdot 87)$.

The number of antihypertensive drug classes used increased from baseline in both study groups ( $\mathrm{p}<0 \cdot 0001)$; however, neither the difference between the groups $(\mathrm{p}=0.79)$ or the time-by-group interaction was significant $(\mathrm{p}=0 \cdot 22)$. On average, $2 \cdot 0$ (SD 1.00) drug classes were used in both groups at randomisation, $2 \cdot 8(1 \cdot 01)$ classes 


\begin{tabular}{|c|c|c|c|c|}
\hline & $\begin{array}{l}\text { Usual } \\
\text { control } \\
(n=553)\end{array}$ & $\begin{array}{l}\text { Tight } \\
\text { control } \\
(n=557)\end{array}$ & $\mathrm{HR}(95 \% \mathrm{Cl})$ & p value \\
\hline $\begin{array}{l}\text { Death from any cause, MI, stroke, TIA, atrial } \\
\text { fibrillation, admission for heart failure, angina, or } \\
\text { coronary revascularisation* }\end{array}$ & $52(9 \cdot 4 \%)$ & $27(4 \cdot 8 \%)$ & $0.50(0.31-0.79)$ & 0.003 \\
\hline $\begin{array}{l}\text { Death from any cause, MI, stroke, admission for } \\
\text { heart failure, angina, or coronary revascularisation } †\end{array}$ & $32(5 \cdot 8 \%)$ & $17(3 \cdot 0 \%)$ & $0.51(0.29-0.93)$ & 0.027 \\
\hline \multicolumn{5}{|l|}{ Single components of composite outcomes } \\
\hline Coronary revascularisation & $15(2 \cdot 7 \%)$ & $5(0.9 \%)$ & $0.33(0.12-0.91)$ & 0.032 \\
\hline New-onset atrial fibrillation & $21(3 \cdot 8 \%)$ & $10(1 \cdot 8 \%)$ & $0.46(0.22-0.98)$ & 0.044 \\
\hline MI & $6(1 \cdot 1 \%)$ & $4(0.7 \%)$ & $0.66(0.19-2 \cdot 34)$ & 0.52 \\
\hline Admission for heart failure & $7(1 \cdot 3 \%)$ & $3(0.5 \%)$ & $0.42(0.11-1.63)$ & 0.21 \\
\hline Stroke or TIA & $9(1.6 \%)$ & $4(0 \cdot 7 \%)$ & $0.44(0.13-1.42)$ & 0.16 \\
\hline Death from any cause & $5(0.9 \%)$ & $4(0.7 \%)$ & $0.77(0.21-2.88)$ & 0.70 \\
\hline
\end{tabular}

Data are number of incident events (\%). $\mathrm{HR}=$ hazard ratio. $\mathrm{MI}=$ myocardial infarction. $\mathrm{TI} \mathrm{A}=$ transient ischaemic attack. *Pre-defined secondary outcome. †Post-hoc defined composite outcome, which does not include transient ischaemic attack and atrial fibrillation.

Table 2: Incidence of the secondary outcome, its components, and death from any cause by randomisation group baseline and $127(25 \%)$ at 2 years in the usual-control group, and to 107 (19\%) and 118 (23\%) in the tight-control group. We noted a significant increase in the use of statins and aspirin from baseline to 2-year follow-up (both $\mathrm{p}<0.0001$ ), without any statistical difference between the two groups $(\mathrm{p}=0.94$ for aspirin and $\mathrm{p}=0.47$ for statins).

\section{Discussion}

Findings from our trial have shown that setting a systolic target of less than $130 \mathrm{~mm} \mathrm{Hg}$ instead of the usual $140 \mathrm{~mm} \mathrm{Hg}$ in patients with treatment-resistant systolic hypertension was feasible and well tolerated. Over 2 years, tight compared with usual blood-pressure control in non-diabetic patients with uncontrolled hypertension at baseline resulted in a reduction in systolic blood pressure. This reduction decreased the likelihood of left ventricular hypertrophy and the incidence of the prespecified composite cardiovascular outcome.

Seven trials, ${ }^{6-11,20,21}$ of which two are still in progress, ${ }^{11,21}$ aimed to show the potential benefits of tight versus usual blood-pressure control. Only the Japanese trial to assess optimal systolic blood pressure in elderly hypertensive patients (JATOS) ${ }^{20}$ was specifically designed to compare tight $(<140 \mathrm{~mm} \mathrm{Hg}$ ) with moderate $(140-160 \mathrm{~mm} \mathrm{Hg})$ control of systolic blood pressure irrespective of diastolic blood pressure in hypertensive patients aged $65-85$ years with systolic blood pressure greater than $160 \mathrm{~mm} \mathrm{Hg}$. During the 2-year follow-up, the incidence of cardiovascular events did not differ between the groups. The enrolment of diabetic patients and those aged 80-89 years with complicated hypertension, and the implementation of a treatment schedule mainly based on efonidipine $(51 \cdot 1 \%)$ with underuse of diuretic drugs $(12 \cdot 1 \%)$, might explain the difference between results from JATOS ${ }^{20}$ and our study. Two trials in patients with type 2 diabetes $^{7-9}$ had either only diastolic blood pressure goals $^{8,9}$ or both systolic and diastolic blood pressure goals. ${ }^{7}$ The United Kingdom Prospective Diabetes Study (UKPDS) ${ }^{7}$ was undertaken exclusively in hypertensive patients with diabetes. In the Hypertension Optimal Treatment Trial (HOT), ${ }^{6}$ better control of diastolic blood pressure resulted in a reduction of the composite cardiovascular endpoint only in the subset of 1501 patients with diabetes (incidence $9.0 \%$ with the blood pressure goal $<90 \mathrm{~mm} \mathrm{Hg}, 6 \cdot 8 \%$ with goal $<85 \mathrm{~mm} \mathrm{Hg}$, and $4.4 \%$ with goal $<80 \mathrm{~mm} \mathrm{Hg}$; $=0 \cdot 005) .{ }^{6}$ The Afro-American Study of Kidney Disease and Hypertension (AASK) ${ }^{10}$ was undertaken in black hypertensive patients with nephropathy.

We powered our study on left ventricular hypertrophy as the primary outcome. Although usually described as an intermediate endpoint, electrocardiographic left ventricular hypertrophy is a powerful and independent predictor of outcome when diagnosed at one visit ${ }^{22}$ or as a trend over time..$^{15,16,23}$ In the Framingham Heart study, ${ }^{15}$ patients with left ventricular hypertrophy at baseline and 


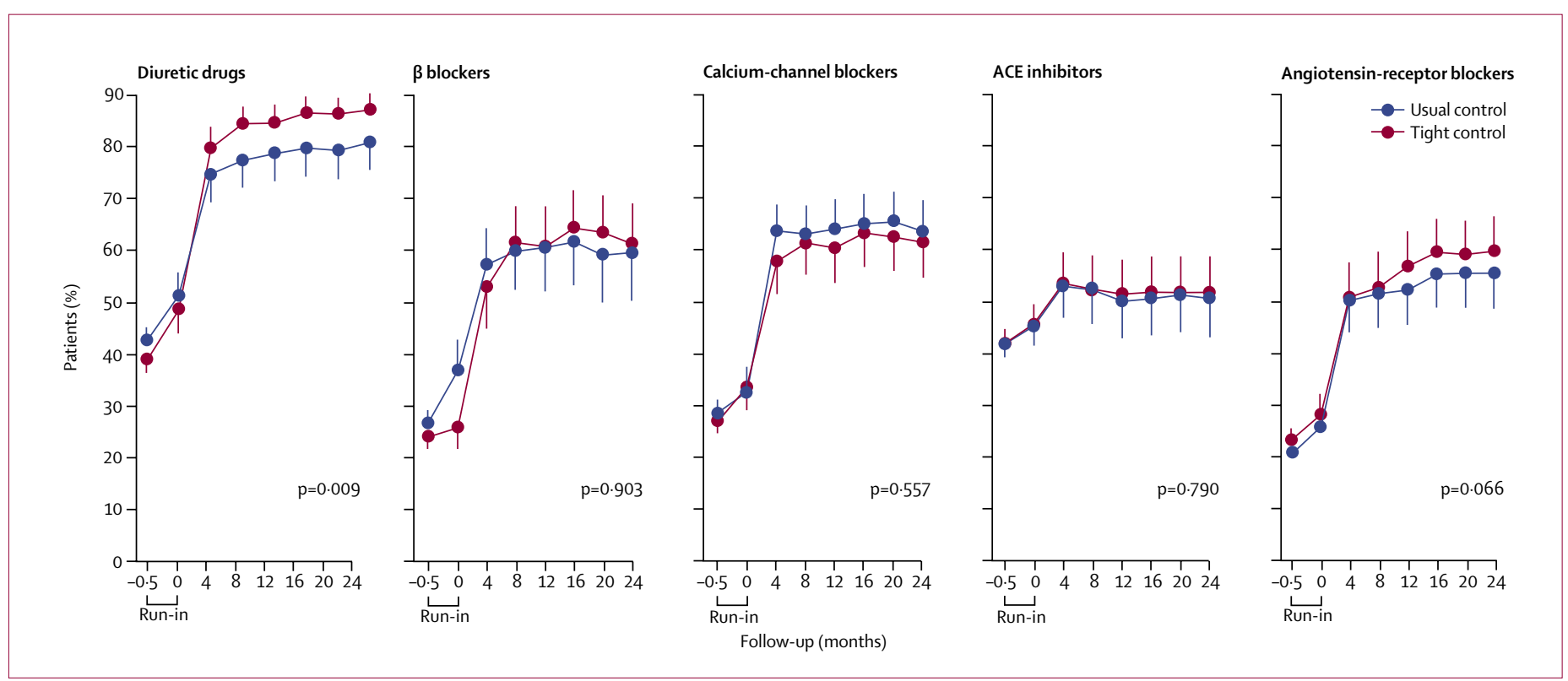

Figure 5: Percentage of patients in the usual-control and tight-control groups treated at baseline and follow-up with various classes of antihypertensive drugs Error bars denote $95 \% \mathrm{Cls}$. ACE=angiotensin-converting enzyme.

a serial increase over time in the electrocardiographic voltages were twice as likely to have a cardiovascular event during the subsequent 2 years than were those with a decrease in the voltages. The primary objective of the double-blind Heart Outcomes Prevention (HOPE) trial $^{24,25}$ was to show benefit beyond blood-pressure lowering of the angiotensin-converting enzyme inhibitor ramipril, which was given in addition to usual treatment in high-risk patients with normal or modestly increased blood pressure. Systolic blood pressure was $3 \mathrm{~mm} \mathrm{Hg}$ lower with ramipril than with placebo. ${ }^{25}$ Electrocardiographic left ventricular hypertrophy was defined by voltage criteria, ${ }^{23}$ and it was not one of the predefined outcomes. ${ }^{24}$ Electrocardiographic left ventricular hypertrophy was present at baseline in $8 \%$ of patients $(676 / 8281)$ and it was reduced by $17 \%$ with ramipril compared with placebo after 5 years of treatment (HR 0.83, 95\% CI 0.72-0.95; $\mathrm{p}=0 \cdot 008$ ). ${ }^{23}$ Prevalence of left ventricular hypertrophy at baseline was lower in HOPE than in Cardio-Sis, which was consistent with the lower blood pressure at baseline in patients in the HOPE trial.

In our present study, the use of antihypertensive drugs during follow-up increased equally in the two groups, indicating an aggressive therapeutic strategy. Furthermore, the use of aspirin and statins increased equally in the two groups. Diuretic drugs and, to a lesser extent, angiotensin-receptor blockers were more frequently used in the tight-control group than in the usual-control group. Since the use of specific classes of drugs was not driven by protocol but was left to the judgment of investigators, these findings could indicate a tendency towards the use of diuretic drugs and angiotensin-receptor blockers to achieve a tight control of systolic blood pressure.
Although the number of events of clinical outcome was small, coronary revascularisation and episodes of new-onset atrial fibrillation were significantly less frequent in the tight-control group than in the usual-control group. The lower risk of new-onset atrial fibrillation in the tight-control group is consistent with the reported association between the risk of atrial fibrillation and poor control of systolic blood pressure. ${ }^{26}$

Our trial has to be interpreted within the context of its potential limitations and strengths. First, we based the diagnosis of left ventricular hypertrophy on the electrocardiogram, which is less sensitive than is echocardiography. ${ }^{27}$ However, we centralised and standardised the reading of the electrocardiograms and based the diagnosis of electrocardiographic left ventricular hypertrophy on the validated Perugia score, ${ }^{17,18}$ which incorporates both voltages and repolarisation, rather than on simple voltage criteria. In a longitudinal study of hypertensive patients with left ventricular hypertrophy at baseline diagnosed by this score, patients with regression of left ventricular hypertrophy at follow-up had a 54\% reduced risk of primary outcome events. In overweight and obese individuals randomly assigned in the Losartan Intervention For Endpoint Reduction (LIFE) study, ${ }^{28}$ the diagnostic performance of the Perugia score ${ }^{17,18}$ was better than that of the Sokolow-Lyon index ${ }^{29}$ and similar to that of the Cornell voltage-duration product. ${ }^{27}$

Second, since this study was not double blind, awareness of the randomisation code could have affected the clinical decisions related to secondary outcome events, especially admission for heart failure and coronary revascularisation. Third, since the study has been entirely undertaken in white patients, extrapolation to other ethnic groups, such as African-Americans, ${ }^{10}$ 
might not be justified. Fourth, we did not include patients with diabetes mellitus-a group for which present guidelines based on the already available evidence ${ }^{6-9}$ recommend tight pressure control. ${ }^{3-5}$ Finally, although the secondary clinical outcome of our study was consistent with the primary outcome of left ventricular hypertrophy, few clinical events occurred because of the fairly small sample size and because the follow-up was limited to 2 years. Our outcome results should therefore be viewed as hypothesis generating, but might potentially be useful for planning large outcome trials focusing on clinical events. The Systolic Blood Pressure Intervention Trial (SPRINT), funded by the US National Institutes of Health, will test the notion that tight control of systolic blood pressure to less than $120 \mathrm{~mm} \mathrm{Hg}$ is better than is usual control to less than $140 \mathrm{~mm} \mathrm{Hg}$ for the prevention of cardiovascular disease. ${ }^{11}$ This trial is still in the planning stage. ${ }^{11}$

In conclusion, tight control of systolic blood pressure to less than $130 \mathrm{~mm} \mathrm{Hg}$ in non-diabetic patients with at least one additional risk factor decreased the likelihood of electrocardiographic left ventricular hypertrophy and clinical events, compared with usual control to less than $140 \mathrm{~mm} \mathrm{Hg}$ systolic. Because of the poor amount of blood-pressure control in the general population and clinical trials, and because of the direct relation between cardiovascular protection and blood-pressure lowering, the results of Cardio-Sis draw attention to the potential benefits of tight blood-pressure control in non-diabetic patients with hypertension.

\section{Contributors}

PV, JAS, FA, AA, GdS, AG, GM, SP, APM, DL, and GR contributed to the design of the study and to the collection and interpretation of the data. GR and FA did the statistical analysis. PV and JAS wrote the first draft of the report. All authors contributed to draft the report and read and approved the final version.

\section{Cardio-Sis study group}

Steering committee Paolo Verdecchia (Chairman), Jan A Staessen, Augusto Achilli, Giovanni de Simone, Antonello Ganau, Gianfrancesco Mureddu, Sergio Pede. Writing committee Paolo Verdecchia, Jan A Staessen, Fabio Angeli, Giovanni de Simone, Aldo P Maggioni and Gianpaolo Reboldi. Endpoint committee Carlo Porcellati, Giovanni Fornari. Coordinating centre ANMCO Research Centre (Aldo P Maggioni, Martina Ceseri, Donata Lucci, Andrea Lorimer). ECG reading centre Associazione Umbra Cuore e Ipertensione (Salvatore Repaci, Claudia Castellani, Giovanni Mazzotta, Silvano Berioli, Carla Jaspers). Clinical record form on-line management Clinical Research Technology (Giovanni Cucchiara, Carlo Panzano). Clinical help on-line Fabio Angeli. Statistical analysis Gianpaolo Reboldi, Fabio Angeli. Participating centres and clinical investigators Aosta (M G Sclavo); Benevento (M Scherillo, D Raucci); Brescia (P Faggiano); Cagliari Brotzu (M Porcu, L Pistis); Caltanissetta (F Vancheri, M Curcio); Casarano (M Ieva, A Muscella); Castiglione del Lago (M Guerrieri, C Dembech); Catania Garibaldi-Nesima (M M Gulizia, G M Francese); Catanzaro (F Perticone, G Iemma); Chiari (G Zanolini); Chieti (S D Pierdomenico, A Mezzetti); Città della Pieve (G Benemio, R Gattobigio, N Sacchi); Città di Castello Cardiologia (M Cocchieri, L Prosciutti); Città di Castello Medicina (O Garognoli); Cremona (S Pirelli, C Emanuelli, G Galeazzi); Erice (M G Abrignani, R Lombardo, G B Braschi); Genova DIMI (G Leoncini); Gorizia (D Igidbashian, R Marini); Gubbio (S Mandorla, M Buccolieri, L Picchi); Lido di Camaiore (G Casolo, M Pardini); Napoli Policlinico Federico II (F Galletti, A Barbato); Perugia (C Cavallini, C Borgioni, M G Sardone); Pistoia (F Cipollini, G Seghieri, E Arcangeli);
Poggibonsi (W Boddi, C Palermo); Pozzilli (G Lembo); Ragusa (L Malatino); Reggio Calabria (D Leonardis); Roma San Camillo (C Gentile); Roma San Giovanni (A Boccanelli, G F Mureddu); Roma San Filippo Neri (F Colivicchi); Roma CTO (M Uguccioni); Sacile (G Zanata, G Martin); San Daniele del Friuli (L Mos, S Martina, V Dialti); San Pietro Vernotico (S Pede, S A Pede); Sassari (A Ganau, G Farina); Scilla (E Tripodi, B Miserrafiti); Siracusa (M Stornello, E V Valvo); Terni (G Proietti, M Bernardinangeli); Thiesi (G Poddighe, M A Marras); Todi (B Biscottini, R Panciarola); Torino (F Veglio, P Mulatero, M A Caserta); Trebisacce (M Chiatto); Trento (G Cioffi, G Bonazza); Viterbo (A Achilli, P Achilli).

\section{Conflicts of interest}

PV, FA, and GR received consulting and lecturing fees from Boehringer-Ingelheim and Sanofi-Aventis. AM and DL received research support from Boehringer-Ingelheim, Sanofi-Aventis, and Pfizer. JAS received consulting and lecturing fees and research support from AstraZeneca, Daiichi-Sankyo, Mitsubishi Tanabe Pharma, Novartis, Pfizer, and Sigma-Tau. GM, AA, GdS, AG, and SP declare that they have no conflicts of interest.

\section{Acknowledgments}

Cardio-Sis was an investigator-initiated study supported by Associazione Nazionale Medici Cardiologi Ospedalieri (ANMCO) through grants from Boehringer-Ingelheim, Sanofi-Aventis, and Pfizer to ANMCO. We thank T Richart (Leuven, Belgium) for preparing the figures; and Sandra Covens and Ya Zhu (Leuven, Belgium) for their expert assistance in preparing the report for submission.

\section{References}

1 Prospective Studies Collaboration. Age-specific relevance of usua blood pressure to vascular mortality: a meta-analysis of individua data for one million adults in 61 prospective studies. Lancet 2002; 360: 1903-13.

2 Staessen JA, Wang JG, Thijs L. Cardiovascular protection and blood pressure reduction: a meta-analysis. Lancet 2001; 358: 1305-15.

3 Mancia G, De Backer G, Dominiczak A, et al. 2007 guidelines for the management of arterial hypertension. The task force for the management of arterial hypertension of the European Society of Hypertension (ESH) and of the European Society of Cardiology (ESC). J Hypertens 2007; 25: 1105-87.

4 Chobanian AV, Bakris GL, Black BK, et al. The seventh report of the Joint National Committee on Prevention, Detection, Evaluation, and Treatment of High Blood Pressure. The JNC 7 Report. JAMA 2003; 289: 2560-72.

5 Williams B, Poulter NR, Brown MJ, et al. British Hypertension Society guidelines for hypertension management 2004 (BHS-IV): summary. BMJ 2004; 328: 634-40

6 Hansson L, Zanchetti A, Carruthers SG, et al. Effects of intensive blood-pressure lowering and low-dose aspirin in patients with hypertension: principal results of the Hypertension Optimal Treatment (HOT) randomised trial. Lancet 1998; 351: 1755-62.

7 UK Prospective Diabetes Study Group. Tight blood pressure contro and risk of macrovascular and microvascular complications in type 2 diabetes: UKPDS 38. BMJ 1998; 317: 703-13.

8 Estacio RO, Jeffers BW, Gifford N, Schrier RW. Effect of blood pressure control on diabetic microvascular complications in patients with hypertension and type 2 diabetes. Diabet Care 2000; 23 (suppl 2): B54-64.

9 Schrier RW, Estacio RO, Esler A, Mehler P. Effects of aggressive blood pressure control in normotensive type 2 diabetic patients on albuminuria, retinopathy and strokes. Kidney Intern 2002; 61: 1086-97.

10 Wright JT Jr, Bakris G, Greene T, et al. Effect of blood pressure lowering and antihypertensive drug class on progression of hypertensive kidney disease. Results from the AASK trial. JAMA 2002; 288: 2421-31.

11 Zanchetti A, Mancia G, Black HR, et al. Facts and fallacies of blood pressure control in recent trials: implications in the management of patients with hypertension. J Hypertens 2009; 27: 673-79.

12 Cardio-Sis Study Group. Randomized study of traditional versus aggressive systolic blood pressure control (Cardio-Sis): rationale, design and characteristics of the study population. J Hum Hypertens 2008; 22: 243-51. 
13 Franklin SS, Larson MG, Khan SA, et al. Does the relation of blood pressure to coronary heart disease change with aging? The Framingham Heart Study. Circulation 2001; 103: 1245-49.

14 Lloyd-Jones DM, Evans JC, Larson MG, O’Donnell CJ, Roccella EJ, Levy D. Differential control of systolic and diastolic blood pressure: factors associated with lack of blood pressure control in the community. Hypertension 2000; 36: 594-99.

15 Levy D, Salomon M, D'Agostino RB, Belanger AJ, Kannel WB. Prognostic implications of baseline electrocardiographic features and their serial changes in subjects with left ventricular hypertrophy. Circulation 1994; 90: 1786-93.

16 Verdecchia P, Reboldi G, Angeli F, et al. Prognostic value of serial electrocardiographic voltage and repolarization changes in essential hypertension: the HEART survey study. Am J Hypertens 2007; 20: 997-1004

17 Verdecchia P, Schillaci G, Borgioni C, et al. Prognostic value of a new electrocardiographic method for diagnosis of left ventricular hypertrophy in essential hypertension. J Am Coll Cardiol 1998; 31: $383-90$.

18 Schillaci G, Verdecchia P, Borgioni C, et al. Improved electrocardiographic diagnosis of left ventricular hypertrophy. Am J Cardiol 1994; 74: 714-19.

19 Romhilt DW, Estes EH Jr. A point-score system for the ECG diagnosis of left ventricular hypertrophy. Am Heart J 1968; 75: 752-58.

20 JATOS study group. Principal results of the Japanese trial to assess optimal systolic blood pressure in elderly hypertensive patients (JATOS). Hypertens Res 2008; 31: 2115-27.

21 Fujiwara T, Nishimura T, Ohkubo T, Imai Y, HOMED-BP study group. Rationale and design of HOMED-BP study: hypertension objective treatment based on measurement by electrical devices of blood pressure study. Blood Press Monit 2002; 7: 77-82.
22 Kannel WB, Gordon T, Castelli WP, Margolis JR. Electrocardiographic left ventricular hypertrophy and risk of coronary heart disease. The Framingham study. Ann Intern Med 1970; 72: 813-22.

23 Mathew I, Sleight P, Lonn E, et al. Reduction of cardiovascular risk by regression of electrocardiographic markers of left ventricular hypertrophy by the angiotensin-converting enzyme inhibitor ramipril. Circulation 2001; 104: 1615-21.

24 The Hope Study Investigators. The HOPE (Heart Outcomes Prevention Evaluation) study: the design of a large, simple randomized trial of an angiotensin-converting enzyme inhibitor (ramipril) and vitamin $\mathrm{E}$ in patients at high risk of cardiovascular events. Can J Cardiol 1996; 12: 127-37.

25 The Heart Outcomes Prevention Evaluation Study Investigators. Effects of an angiotensin-converting-enzyme inhibitor, ramipril, on cardiovascular events in high-risk patients. N Engl J Med 2000; 342: 145-53.

26 Thomas MC, Kaplan RC, Glazer NL, et al. Blood pressure control and risk of incident atrial fibrillation. Am J Hypertens 2008; 21: 1111-16.

27 Casale PN, Devereux RB, Kligfield P, et al. Electrocardiographic detection of left ventricular hypertrophy: development and prospective validation of improved criteria. J Am Coll Cardiol 1985; 6: $572-80$.

28 Okin PM, Jern S, Devereux RB, Kjeldsen SE, Dahlöf B, for The LIFE Study Group. Effect of obesity on electrocardiographic left ventricular hypertrophy in hypertensive patients. The Losartan Intervention For Endpoint (LIFE) reduction in hypertension study. Hypertension 2000; 35: 13-18.

29 Sokolow M, Lyon TP. The ventricular complex in left ventricular hypertrophy as obtained by unipolar precordial and limb leads. Am Heart J 1949; 37: 161-86. 